\title{
The impact of carbon materials on the hydrogen storage properties of light metal hydrides
}

\author{
Philipp Adelhelm*a and Petra E. de Jongh ${ }^{b}$ \\ Received 9th August 2010, Accepted 28th September 2010 \\ DOI: $10.1039 / \mathrm{c} 0 \mathrm{jm} 02593 \mathrm{c}$
}

\begin{abstract}
The safe and efficient storage of hydrogen is still one of the remaining challenges towards fuel cell powered cars. Metal hydrides are a promising class of materials as they allow the storage of large amounts of hydrogen in a small volume at room temperature and low pressures. However, usually the kinetics of hydrogen release and uptake and the thermodynamic properties do not satisfy the requirements for practical applications. Therefore current research focuses on catalysis and the thermodynamic tailoring of metal hydride systems. Surprisingly, carbon materials used as additive or support are very effective to improve the hydrogen storage properties of metal hydrides allowing fast kinetics and even a change in the thermodynamic properties. Even though the underlying mechanisms are not always well understood, the beneficial effect is probably related to the peculiar structure of the carbon materials. This feature article gives an introduction to the different carbon materials, an overview of the preparation strategies to synthesize carbon/hydride nanocomposites, and highlights the beneficial effect of carbon by discussing two important hydrides: $\mathrm{MgH}_{2}$ and $\mathrm{NaAlH}_{4}$.
\end{abstract}

\section{Introduction}

The use of hydrogen as an energy carrier in the transportation sector holds great prospects in order to reduce $\mathrm{CO}_{2}$ emissions and the dependency on fossil fuels. For a medium-sized, fuel cell powered car, only around $4 \mathrm{~kg}$ of $\mathrm{H}_{2}$ would be needed to reach a driving range of $400 \mathrm{~km} .{ }^{1}$ However, due to the peculiarities of hydrogen, the development of a suitable tank system is very challenging. The use of metal hydrides for the solid state storage of hydrogen is promising mainly because they allow the storage

anstitute of Physical Chemistry, Justus-Liebig-University Giessen Heinrich-Buff-Ring 58, 35392 Giessen, Germany. E-mail: philipp. adelhelm@uni-giessen.de

${ }^{b}$ Inorganic Chemistry and Catalysis, Debye Institute for Nanomaterials Science, Utrecht University, Sorbonnelaan 16, 3584 CA Utrecht, The Netherlands.E-mail: p.e.dejongh@uu.nl of large amounts of hydrogen at low $\mathrm{H}_{2}$ pressures in a small volume. The hydrogen content of magnesium hydride is $7.7 \mathrm{wt} \%$ with a hydrogen density of $110 \mathrm{~g} \mathrm{~L}^{-1}$, for example (i.e. a $\mathrm{MgH}_{2}$ block of $52 \mathrm{~kg}$ and $36 \mathrm{~L}$ contains $4 \mathrm{~kg}$ of hydrogen). The concept of a metal hydride tank system in combination with a fuel cell is illustrated in Fig. 1.

However, the requirements for an actual on-board tank system are plenty and so far no metal hydride system is known that could be applied in practice. ${ }^{2}$ Currently, the main issues are thermodynamic and kinetic limitations.

As the waste heat of a PEM fuel cell should be used to sustain the dehydrogenation reaction of the metal hydride, a suitable metal hydride system should exhibit an enthalpy of formation of $\Delta H=-10$ to $-40 \mathrm{~kJ} \mathrm{~mol}^{-1} \mathrm{H}_{2}$, corresponding to an $\mathrm{H}_{2}$ equilibrium pressure of a few bars during operational conditions (the entropy of the reaction is around $130 \mathrm{~J} \mathrm{~K}^{-1}$ per $\mathrm{mol} \mathrm{H}_{2}$ for all

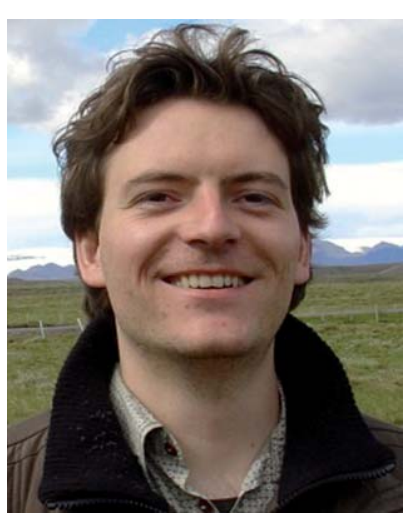

Philipp Adelhelm
Philipp Adelhelm studied materials science at the University of Stuttgart and conducted his PhD at the Max-Planck-Institute of Colloids and Interfaces in Potsdam (Prof. Antonietti). After receiving his $P h D$ in 2007, he joined the group of Petra de Jongh at Utrecht University as a postdoctoral fellow. Currently he is starting up a junior research group at the University of Giessen in the group of Prof. Janek. $H$ is research interests are the preparation and characterization of nanomaterials for hydrogen storage and battery technology.

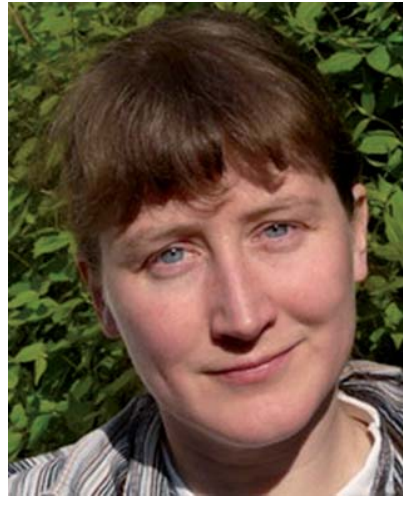

Petra E. de Jongh
Petra de Jongh received her $P h D$ in photoelectrochemistry in 1999, and worked 5 years as a senior scientist at Philips Research. She is now associate professor at Utrecht University, where she (co)-supervises researchers working on supported nanoparticles, especially for applications in catalysis and energy storage and conversion. 


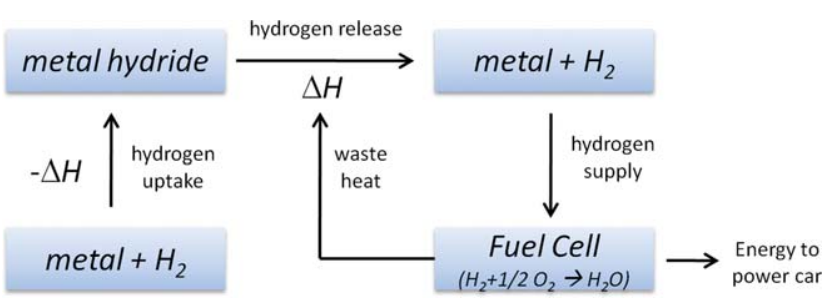

Fig. 1 Principle of a metal hydride tank for the reversible storage of hydrogen. Hydrogen is stored by reaction with a metal to form a hydride (exothermic reaction). On demand, the hydrogen is released from the hydride (endothermic reaction), utilizing the waste heat of the fuel cell.

metal hydride systems if the entropies of the non-gaseous phases are neglected). A few metal hydrides fulfill this requirement a priori, e.g. $\mathrm{LaNi}_{5} \mathrm{H}_{6}(1.4 \mathrm{wt} \% \mathrm{H})$ or $\mathrm{FeTiH}_{2}(1.9 \mathrm{wt} \% \mathrm{H})$, however their hydrogen contents are too small for mobile applications. Metal hydride systems with higher gravimetric densities, namely light metal hydrides or complex hydrides, are usually too stable (e.g. $\mathrm{MgH}_{2}$ with $\Delta H=-75 \mathrm{~kJ} \mathrm{~mol}^{-1} \mathrm{H}_{2}, 7.7$ $\mathrm{wt} \% \mathrm{H}$ ) or too unstable (e.g. $\mathrm{AlH}_{3}$ with $\Delta H=-7.6 \mathrm{~kJ} \mathrm{~mol}^{-1} \mathrm{H}_{2}$, $10.1 \mathrm{wt} \% \mathrm{H})$.

The reactions of hydrogen release und uptake should be fast to allow quick refilling of the tank and sufficient $\mathrm{H}_{2}$ supply of the fuel cell. Current research efforts therefore focus on the improvement of the kinetic behavior and the thermodynamic tailoring of metal hydride systems. Recent approaches include the synthesis of nanostructured composite materials, consisting of a metal hydride phase and an additional phase such as carbon nanotubes, for example. It is believed that by nanosizing, kinetic limitations can be minimized and the thermodynamic stability of the metal hydride system can be modified by size effects or interaction with the additional phase. ${ }^{3-5}$ DFT calculations on $\mathrm{MgH}_{2}$ confined in carbon nanotubes suggest a decrease in $\Delta H$ by $50 \%$, for example. ${ }^{3}$

The three main methods to prepare nanocomposites of metal hydrides are shown in Fig. 2. In ball-milling, a phase is dispersed in the hydride phase, whereas infiltration or impregnation of a porous phase (support) usually lead to a finely dispersed hydride phase. ${ }^{6}$

In both cases, the hydrogen storage properties are improved. Faster hydrogen diffusion is aided by the smaller crystallite size or transport along the other phase. Chemical anchoring or confinement of the metal (hydride) by the additional phase can also suppress the undesired crystal growth that is usually observed for nanomaterials upon cycling. On the other hand, the additional phase adds to the effective weight and volume of the tank system, so its use is only feasible for metal hydrides with relatively high $\mathrm{H}$ contents.

An important question is therefore which material is most suitable as additive/support for metal hydrides. Classical catalysts (transition metals) are effective but can only be used in small fractions, as they are heavy and usually expensive. A structural additive or a support/scaffold comprises a much larger fraction of the composite material so only light and low cost materials can be used. In this respect, carbon materials are outstanding as they are light, relatively inert and often abundant. An exciting property of carbon is its ability to bond with itself (and other atoms) with different hybridizations, giving rise to allotropes of completely different properties. Besides the allotropes, plenty carbon materials exist that offer a wide range of interesting properties. Furthermore, carbon is an efficient heat conductor, which is beneficial to the heat transport during hydride formation and decomposition.

In recent years, carbon materials were reported to lead to improvement in kinetics and thermodynamics of hydrogen sorption for different metal hydride systems. An exciting example for the impact on the kinetics of the hydrogen release is sodium alanate $\left(\mathrm{NaAlH}_{4}\right)$ 2-10 nm particles deposited on carbon nanofibers, with a decrease in activation energy for the first hydrogen release step from $116 \mathrm{~kJ} \mathrm{~mol}^{-1}$ for bulk to $58 \mathrm{~kJ} \mathrm{~mol}^{-1}$. $^{7}$ Also mixing carbon materials and metal hydrides by high-energy ball-milling (or even simple mixing) improves the hydrogen sorption properties.

The recent developments pinpoint the important role of carbon in the development of new metal hydride based hydrogen storage materials. This review starts with the synthesis and structure of carbon materials, and the background of their possible effects on the hydrogen sorption properties of metal hydrides. Then an overview of the preparation techniques of metal hydride/carbon nanocomposites is given. The strong impact of carbon on the kinetics and thermodynamics of metal hydrides is highlighted for two important systems: $\mathrm{MgH}_{2}$ and $\mathrm{NaAlH}_{4}$. The review will end with a summary on the opportunities and challenges in this field.

\section{What carbon materials can be used?}

To identify the carbon materials that are most suitable as additive/support for metal hydrides, an exact knowledge of their composition and microstructure is desirable. Carbon materials are widely used in industry in form of e.g. porous powders, fibers, fabrics, pellets, extrudates or composites for very different purposes. This is because carbon materials exhibit, depending on their structure, very different properties. For example, diamond $\left(100 \% \mathrm{sp}^{3}\right)$ is used as abrasive due to its hardness and is electronically insulating. In contrast, graphite $\left(100 \% \mathrm{sp}^{2}\right)$ is very soft and can be used as dry lubricant or as conducting agent. Most of the carbon materials used are non-crystalline and are so-called turbostratic (or non-graphitic) carbons. Compared to the crystalline forms of carbon their microstructure is quite complex, they are often porous and can contain other elements as impurities.

Briefly, non-graphitic carbons consist of graphene sheets that pile up to form stacks of a few nanometres in size. Different from graphite, where the graphenes pile up regularly (hexagonal, AB stacking or rhombohedral, ABC stacking), the graphenes in nongraphitic carbons are only more or less parallel packed upon each other (Fig. 3a and b). The graphenes can be embedded in an amorphous matrix and also be connected among each other. The size of the graphene stacks can be estimated by XRD $\left(\mathrm{L}_{\mathrm{a}} \text { and } \mathrm{L}_{\mathrm{c}}\right)^{8}$ or Raman spectroscopy $\left(\mathrm{L}_{\mathrm{a}}\right){ }^{9}{ }^{9}$ Due to their disorder, nongraphitic carbons usually contain a large number of slit-shaped micropores. Typical examples for non-graphitic carbons are activated carbons, carbon aerogels or carbon black.

Activated carbons are usually synthesized by heat treatment of organic matter in inert atmosphere (carbonization or pyrolysis). The use of natural precursors such as coal, wood or 

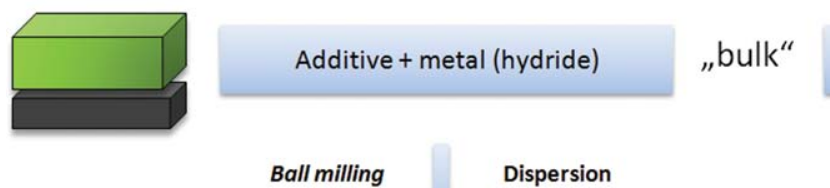

Porous support + metal (hydride)

Solution impregnation

Melt

infiltration

Pore filling

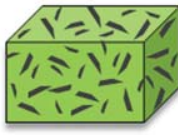

Additive dispersed in metal (hydride)

„Nano"

Supported metal (hydride)

Change in properties due to:

particle size, pore size, confinement, clamping, thermal conductivity, reaction or interaction with additive/support, charge transfer, diffusion along second phase ..

Improved $\mathrm{H}_{2}$ storage

properties?

Fig. 2 The hydrogen storage properties of metal hydrides can be tailored by mixing with an additive (usually ball-milling) or by supporting on a porous material using solution impregnation or melt infiltration. The resulting nanocomposites exhibit different properties compared to the bulk metal hydrides.

coconut shell allows a low cost production and is the reason for their widespread use. The high surface area is obtained by activation processes such as steam activation. Typically, activated carbons are highly microporous $(d<2 \mathrm{~nm})$ with a broad pore size distribution, and exhibit surface areas between 500 and $1200 \mathrm{~m}^{2} \mathrm{~g}^{-1}$. a

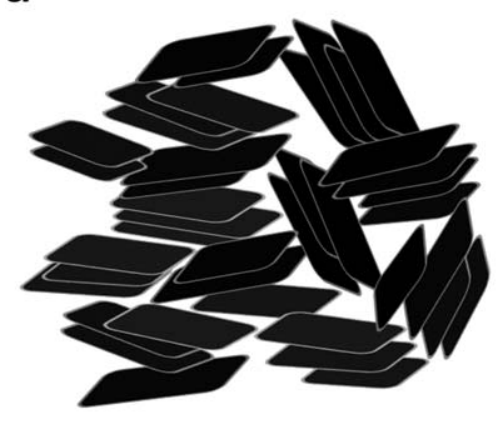

b

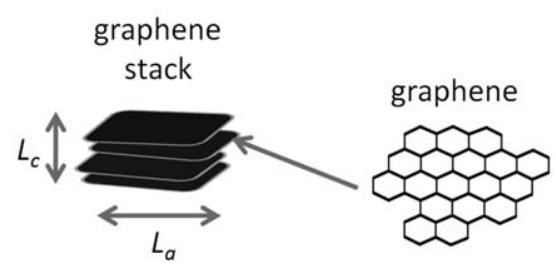

C<smiles>C#CC#CC#C</smiles>

MW-CNT

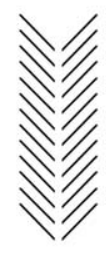

CNF
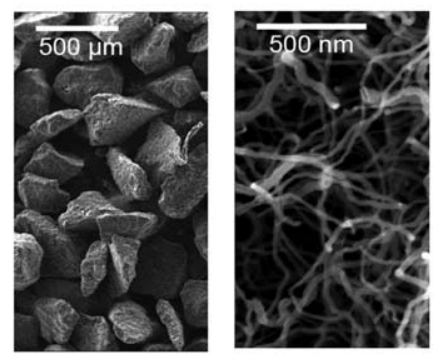

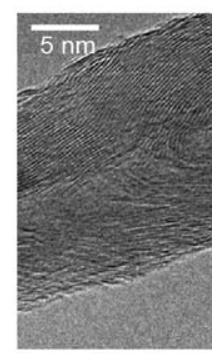

Fig. 3 (a) Sketch of the microstructure in turbostratic carbon materials. (b) Illustration of a single graphene stack. The dimensions are described by layer size $L_{a}$ and stack height $L_{c}$. (c) left: Orientation of the graphenes in carbon nanotubes and nanofibers. right: SEM and TEM images of carbon nanofibers, reprinted by permission of the publisher (Taylor \& Francis Group). 
Carbon black consists of spherically shaped carbon nanoparticles and their fused aggregates, synthesized by incomplete combustion or thermal decomposition of gaseous/liquid hydrocarbons. Oils, natural gas or acetylene usually serve as feedstock. Carbon blacks can be synthesized with surface areas up to $1500 \mathrm{~m}^{2} \mathrm{~g}^{-1}$ and are industrially used as reinforcing fillers, pigments or conducting agents, for example. ${ }^{10,11}$

Carbon aerogels (cryogels, xerogels) can be described as mesoporous $(d=2-50 \mathrm{~nm})$ networks that are formed by loosely connected carbon nanoparticles. The mesopore volume of carbon aerogels can be quite large $\left(>0.55 \mathrm{~cm}^{3} \mathrm{~g}^{-1}\right)$. Carbon aerogels are synthesized by careful carbonization of organic aerogels (resorcinol/formaldehyde or phenol/furfural aerogels) under inert atmosphere and can be obtained in monolithic form. Depending on the synthesis parameters, the mesopore size can be adjusted. Carbon aerogels typically exhibit surface areas between 600 and $800 \mathrm{~m}^{2} \mathrm{~g}^{-1}$ and a relatively large micropore volume. $^{12-15}$

Carbon materials with monodisperse pores of a particular shape in the nanometre range are more difficult to realize, however, they are desired to study size effects. Ordered and disordered porous carbon materials with defined porosity can be synthesized using the templating method, also known as nanocasting. Thereto, a porous template $\left(\mathrm{SiO}_{2}\right.$ or zeolite) is first impregnated with a carbon precursor. After carbonization of the precursor and dissolution of the template, a porous carbon replica is obtained. ${ }^{16}$ Depending on the template and carbon precursor, carbon replicas with different pore sizes can be synthesized, e.g. CMK-3 with ordered mesopores of $4.5 \mathrm{~nm}$ in diameter is a replica of SBA-15 (silica). ${ }^{17,18}$ In another approach, silica nanoparticles are dispersed in the carbon precursor prior to carbonization. Also polymers have been used as porogen. ${ }^{19}$

Carbide derived carbons (CDCs) are microporous carbons with defined pore size and controllable pore volume and are synthesized by selective thermo-chemical etching of metal atoms from carbides. ${ }^{20,21}$

Carbon materials with medium high surface areas and very well defined structure are carbon nanofibers (CNFs) and carbon nanotubes (CNTs). CNFs and CNTs typically exhibit surface areas between 10 and $400 \mathrm{~m}^{2} \mathrm{~g}^{-1}$ and diameters between 10 and $200 \mathrm{~nm} .{ }^{22,23}$ Both can be synthesized by the catalytic decomposition of carbon containing gases (e.g. $\mathrm{CH}_{4}, \mathrm{CO}, \mathrm{C}_{2} \mathrm{H}_{4}$ ), using small metal particles as the growth catalyst. An interesting feature is that their surfaces exhibit exclusively either the basal planes (CNT) or edge planes (CNF) of the graphenes. Fullerenes are another class of well defined carbon materials with spherical structure build of hexagonal and pentagonal rings. A diameter of $0.78 \mathrm{~nm}$ is reported for C60, for example. ${ }^{24,25}$
Fig. 3 gives an overview of the structure of different carbon materials. A selection of carbon materials and their properties are summarized in Table 1.

\section{Synthesis strategies}

The most frequently used method to prepare carbon/metal hydride nanocomposites is ball-milling. Ball-milling reduces the particle/crystallite size of metal (hydrides) ${ }^{26-31}$ down to around 20-30 $\mathrm{nm}$ and introduces many defects and amorphous areas that enhance diffusion processes. However, the "nanoeffect" is usually lost upon cycling due to crystal growth. ${ }^{32,33}$ In ballmilling, carbon is used as an additive (typically $5-15 \mathrm{wt} \%$ ) that is dispersed in the metal (hydride) phase during the milling process rather than a support. Many different carbon materials among CNTs, $\mathrm{C}_{60}$, graphite, carbon blacks, activated carbons and ordered mesoporous carbons have been investigated and generally speaking all of them show positive effects on the hydrogen sorption properties. However, care has to be taken when interpreting the results, as ball-milling can destroy the carbon structure (amorphization) ${ }^{34}$ and certain carbon materials contain classical catalysts as impurities. CNTs and CNFs can contain $\mathrm{Ni}$, $\mathrm{Co}$ or Fe impurities, for example that can get into contact with the metal (hydride) phase due to destruction of the tubes upon ball-milling. ${ }^{35,36}$ Also the ball mill vial or the (typically steel) balls are sources for contaminations. ${ }^{37}$

The main routes to prepare carbon supported metal hydrides are solution impregnation and melt infiltration. To be suitable as a support, the carbon material should exhibit (1) a high surface area, (2) an accessible pore system and (3) a large total porosity in order to allow high weight loadings of metal hydride. To study the size effects and interaction with the support, a defined pore size and surface are desirable.

In solution impregnation, a solution of the hydride or a precursor is used to infiltrate the porous carbon material. Then, the solvent is evaporated to leave finely dispersed nanoparticles on the support. This technique is well known from catalyst preparation and has the advantage that relatively small nanoparticles $(<10 \mathrm{~nm})$ of defined size can be prepared. A main drawback is that the synthesis involves a multi-step procedure and higher loadings of metal (hydride) can be often only obtained by multiple impregnation and drying, as for many compounds the solubility is low. Thus, concerning hydrogen storage materials, solution impregnation is an excellent technique to synthesize model systems; however, other methods are needed to synthesize larger quantities more cost-effective.

Melt infiltration allows the synthesis of higher weight loadings in a single step. Here, the metal or metal hydride is melted under

Table 1 Selection of carbon materials that can be used as additive or support for metal hydrides

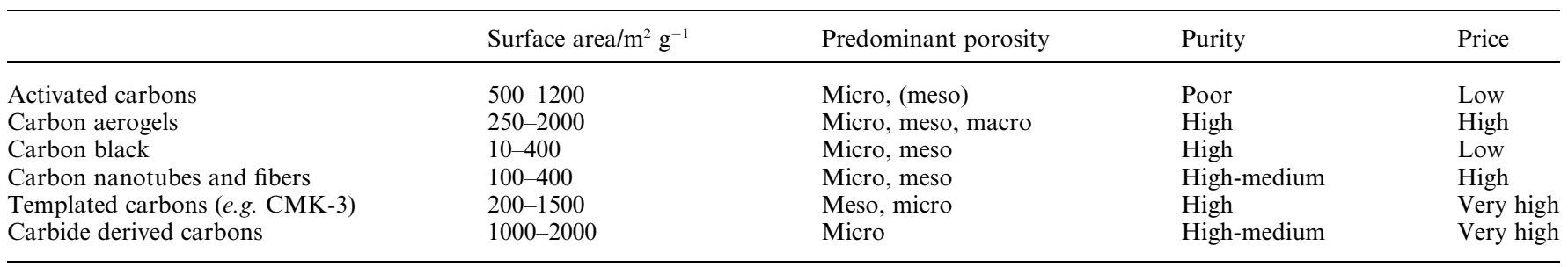


appropriate conditions. In case of wetting, i.e. the contact angle of the melt on the support is smaller $90^{\circ}$, the pores of the support are filled by capillary force. After cooling and solidification, the metal (hydride) is confined in the pores of the support. Ideally, the particle size is defined by the pore size of the support. In nanopores, the capillary pressure can be as high as 1000 bar, so the driving force for pore filling is very high. On the contrary, in the case of non-wetting (contact angle of the melt $>90^{\circ}$ ), external pressure has to be applied to fill the pores of the support. ${ }^{38}$

\section{Potential impact of the carbon supports/additives}

Carbon materials exhibit certain properties that make them in combination with metal hydrides more suitable compared to other potential supports or additives. An important property is their relative chemical inertness, especially because light metal hydrides are chemically very reactive. However, some possible reactions/interactions with a carbon matrix do exist among the most important ones are intercalation, carbide formation and interactions with terminating groups or defects. In some cases, these interactions are beneficial to the hydrogen sorption properties of metal hydrides, in others they are unwanted. Also, the ability of carbon to efficiently conduct heat and the fast $\mathrm{H}_{2}$ diffusion along the carbon phase can improve the hydrogen sorption properties.

\section{Intercalation}

A well known property of graphite (and non-graphitic carbon materials) is the ability to form lamellar intercalation compounds with many species, in particular alkali metals. ${ }^{39-41} \mathrm{~A}$ technologically important graphite intercalation compound is $\mathrm{LiC}_{6}$ which forms the negative electrode material in today's lithium ion batteries. The intercalation/deintercalation process is highly reversible and can allow thermodynamic tailoring of a metal (hydride) system. As the intercalation process is exothermic $\left(\Delta H=-13.9 \mathrm{~kJ} \mathrm{~mol}^{-1}[\mathrm{Li}]\right.$ for $\left.\mathrm{LiC}_{6}\right),{ }^{42}$ the metal phase is stabilized towards the hydride phase and consequently $\Delta H$ for the de-/hydrogenation reaction is reduced. This principle was recently demonstrated for the hydrogen release from $\mathrm{NaH} .{ }^{43}$ Also, ternary intercalation compounds of hydrogen/alkali metal/ graphite are known. ${ }^{44}$

\section{Carbide and methane formation}

Carbide formation $\left(\mathrm{Li}_{2} \mathrm{C}_{2}, \mathrm{Na}_{2} \mathrm{C}_{2}, \mathrm{CaC}_{2}, \ldots\right)$ is thermodynamically favored for certain light metals, however, they form only at higher temperatures due to kinetic limitations. $\mathrm{Li}_{2} \mathrm{C}_{2}$ formation starts at $\sim 400{ }^{\circ} \mathrm{C}$, for example. In principle, carbide formation is undesired, as the carbon structure is destroyed and metal hydride formation from the carbide phase is likely to be difficult. Some reports do exist on graphite/LiH nanocomposites, ${ }^{45,46}$ and carbon/ $/ \mathrm{LiBH}_{4}$ nanocomposites ${ }^{47}$ where hydrogen uptake and release involve the formation of $\mathrm{Li}_{2} \mathrm{C}_{2}$. However, it was found that $\mathrm{CH}_{4}$ can form during cycling, i.e. the carbon content gradually decreases upon cycling. ${ }^{45}$ Thermodynamically, methane formation is favorable for systems involving $\mathrm{H}_{2}$ and $\mathrm{C}$ and can occur at elevated temperatures, especially when catalytic species are present. This can become relevant when the hydrogenation is conducted at high temperatures and high hydrogen pressures. ${ }^{45}$

\section{Terminating groups, defects and contamination}

Whether solution impregnation or melt infiltration is used as synthesis method, wetting of the support is crucial and can be adjusted by the surface chemistry of the carbon materials. As the edges of the graphenes need to be terminated, non-graphitic carbons contain a certain amount of other atoms, usually $\mathrm{H}, \mathrm{O}$ and $\mathrm{N}$ that determine the surface energy and thus the interaction with other phases. Nature and concentration of the terminating species can vary depending on the carbon precursor, carbonization temperature or chemical post-treatment. ${ }^{48-53}$ The terminating species also provide possible sites for chemical reactions with the metal (hydride) phase. Fig. 4 gives an overview over possible oxygen and nitrogen containing terminating groups at the edges of the graphenes. Ideally, CNTs and fullerenes exhibit no terminating groups and thus represent the purest form of carbon nanomaterials.

Also, structural defects within the graphene exist that might be catalytically active. ${ }^{54-56}$ It is suggested that defects in the form of non-hexagonal rings can ease the dissociation of gas molecules. ${ }^{57,58}$ For example, $\mathrm{O}_{2}$ preferentially dissociates at vacancies in graphite. ${ }^{59}$ If the same holds for the dissociation of $\mathrm{H}_{2}$, structural defects in carbon materials would be a powerful tool to improve the hydrogen sorption properties of carbon supported metal hydrides.

The wetting properties and surface energies of the carbon support can be adjusted from hydrophobic "pure" carbon to hydrophilic carbon with hydroxyl terminating groups, for example. For graphite, a surface energy of $0.077 \mathrm{~J} \mathrm{~m}^{-2}$ was found for the basal planes (at $970{ }^{\circ} \mathrm{C}$ ) whereas $4 \mathrm{~J} \mathrm{~m}^{-2}$ was found for the edge planes. ${ }^{61}$ One could therefore expect that CNFs can be wetted easier than CNTs. On the other hand, light metals can irreversibly react with certain surface groups, leading to a loss in active material but facilitate wetting.

Common techniques to determine the amount and/or nature of surface groups are elemental analysis, titration methods, temperature programmed desorption/oxidation, X-ray photoelectron spectroscopy and infrared spectroscopy methods. ${ }^{50-52,62-64}$ Carbon materials also often contain all sorts of impurities, especially when made from natural precursors such as biomass, oil or pitch and metals such as $\mathrm{K}, \mathrm{Fe}, \mathrm{Ni}$, and $\mathrm{Co}^{64}$ that might interact with the metal hydride phase or could act as catalyst.

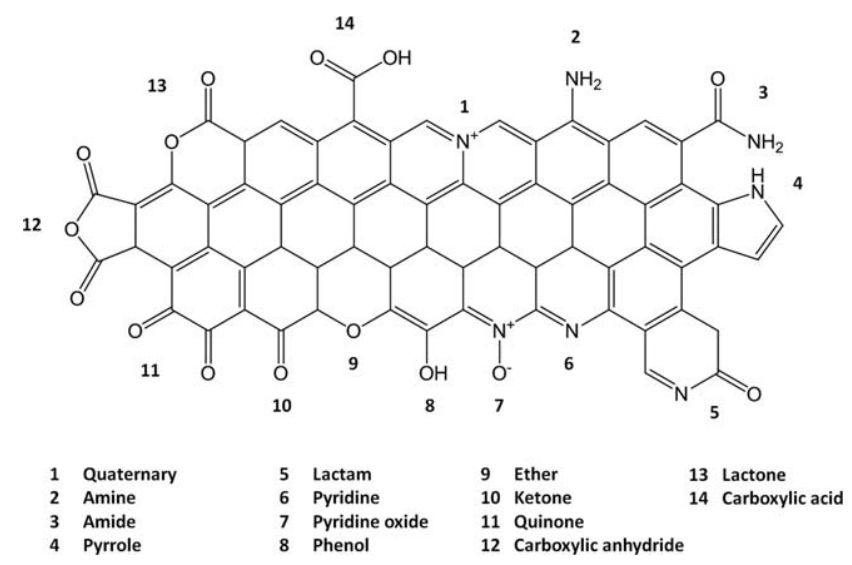

Fig. 4 Possible oxygen and nitrogen species and terminating groups at the edge of a graphene (redrawn from ref. 60). 


\section{$\mathrm{H}_{2}$ diffusion promoter}

Hydrogen diffusion through the bulk metal (hydride) phase is usually quite slow and often rate-limiting. In either case, i.e. metal hydride dispersed over a porous carbon structure, or carbon material dispersed in the metal hydride phase, fast hydrogen diffusion through or along the carbon phase could benefit the kinetics of hydrogen release and uptake.

\section{Thermal conductivity}

The ability of carbon to effectively conduct heat is an important advantage over other inorganic support materials as it enhances the heat exchange during de/rehydrogenation. The thermal conductivity of graphite is highly anisotropic and typically found to be around $12-175 \mathrm{~W} \mathrm{~m}^{-1} \mathrm{~K}^{-1}{ }^{65}$ Even though the effective thermal conductivity depends on many parameters such as particle size, porosity, tank design, etc., it was found that even small amounts of graphite significantly improve the heat conduction of metal hydride compacts. Kim et al. found a thermal conductivity of $>3 \mathrm{~W} \mathrm{~m}^{-1} \mathrm{~K}^{-1}$ for compacts of $\mathrm{LaNi}_{5}$ containing $2 \%$ graphite, ${ }^{66}$ which is much higher than $\sim 0.1 \mathrm{~W} \mathrm{~m}^{-1}$ $\mathrm{K}^{-1}$ that are typically found for metal hydride powders. Sanchez et al. found the thermal conductivity of metal hydride/graphite compacts to be higher compared to when aluminium foams were used as conducting agent. ${ }^{67}$

\section{Dispersion of a catalyst}

Carbon materials can also be used to incorporate additional catalysts to further improve the kinetics of hydrogen release and uptake. $\mathrm{Ni}$ and $\mathrm{Co}$ are well-known catalysts for the dissociation of hydrogen molecules and can easily be dispersed on the carbon support prior to the preparation of the carbon/hydride composite, for example. ${ }^{68,69}$ Also CNTs and CNFs usually contain small amounts of $\mathrm{Ni}$ or $\mathrm{Co}$ nanoparticles that get distributed in the hydride phase during ball milling. ${ }^{70}$

\section{Key results on $\mathrm{MgH}_{2}$ and $\mathrm{NaAlH}_{4}$}

In the following, the beneficial effect of carbon on the hydrogen sorption properties is discussed for a conventional hydride (magnesium hydride- $-\mathrm{MgH}_{2}$ ) and a complex hydride (sodium alanate $-\mathrm{NaAlH}_{4}$ ), as they are among the most studied hydrides and illustrative for many other systems. For studies on the effect of carbon on other hydrogen storage compounds such as $\mathrm{NH}_{3} \mathrm{BH}_{3}$, $\mathrm{LiBH}_{4}$ or $\mathrm{Li}_{3} \mathrm{BN}_{2} \mathrm{H}_{8}$ we refer to the relevant literature. ${ }^{6}$

\section{Magnesium hydride- $\mathrm{MgH}_{2}$}

Magnesium hydride is extensively studied as hydrogen storage material due to its low cost and relatively high hydrogen content of $7.7 \mathrm{wt} \%$. However, its application is hindered by the high stability of the hydride and the poor kinetics of de- and rehydrogenation. The large negative enthalpy of formation of $\Delta H=$ $-75 \mathrm{~kJ} \mathrm{~mol}^{-1}$ corresponds to an equilibrium temperature of $\sim 300{ }^{\circ} \mathrm{C}$ at 1 bar $\mathrm{H}_{2}$. Kinetic limitations lead to practical dehydrogenation temperatures above $400{ }^{\circ} \mathrm{C}$ for bulk $\mathrm{MgH}_{2}$. A significant decrease in the thermodynamic stability is predicted for particle sizes smaller than $\sim 1$ to $2 \mathrm{~nm} .{ }^{71,72}$ As the synthesis of particles smaller than $2 \mathrm{~nm}$ is very challenging, it is an important question whether confinement in a support could further decrease the stability of the hydride. Liang and Kung calculated a reduction of the enthalpy of formation by $50 \%$ for the confinement of $\mathrm{MgH}_{2}$ clusters in $(10,10)$ CNTs of $1.2 \mathrm{~nm}$ in diameter, for example. ${ }^{3}$

So far, most research was devoted to ball-milling of $\mathrm{Mg}\left(\mathrm{H}_{2}\right)$ with different carbon materials, among CNTs, $\mathrm{C}_{60}$, graphite, activated carbons. ${ }^{35,73-77}$ The effect of carbon as additive on the hydrogen release from ball-milled $\mathrm{MgH}_{2}$ is illustrated in Fig. 5. Generally speaking, all carbons show positive effects on the hydrogen sorption properties, i.e. improved kinetics and cycle life, however, the exact mechanism is still a matter of debate. ${ }^{\mathbf{7 0 , 7 7 - 8 0}}$

The addition of graphite to the milling process generally leads to a reduction in crystallite size, which shortens the diffusion paths. However, studies on $\mathrm{Mg}$ nanoparticles with similar size but either milled with graphite or without did not show the same kinetic behavior. It was therefore suggested that graphite prevents the formation of unwanted oxide layers during the ballmilling process that otherwise impede the $\mathrm{H}$ diffusion. ${ }^{75}$ Among the different carbon materials tested, usually CNTs and CNFs show best performance. For example, the rates of hydrogen uptake and release of $\mathrm{Mg}$ milled with CNTs were found to be more than one order of magnitude higher than that of pure $\mathrm{Mg} .{ }^{81}$ It is suggested that added nanotubes act as channels for fast hydrogen diffusion. Accordingly, the catalytic effect decreases upon long milling times once the CNT structure gets destroyed. ${ }^{82}$ The improved performance might be also due to a synergetic effect, as CNTs and CNFs contain metal impurities (Co and Ni) as effective hydrogenation/dehydrogenation catalysts. ${ }^{35,69} \mathrm{On}$ the other hand, investigations on $\mathrm{MgH}_{2} / \mathrm{CNT}$ s composites indicate that the catalytic effect of metal impurities is lost during cycling and the improved cyclability is due to fact that CNTs also prevent particle growth. ${ }^{77}$ Another explanation for the catalytic activity of carbon arises from DFT calculations on a $\mathrm{Mg}(0001)$ surface that includes subsurface carbon atoms. ${ }^{83}$ The calculations suggest that subsurface carbon (which might be incorporated into the metal phase during ball-milling) only slightly affects the dissociation of $\mathrm{H}_{2}$ at the $\mathrm{Mg}$ surface but it facilitates the diffusion of atomic hydrogen into the subsurface by lowering the transport activation barriers. A more detailed discussion on the kinetic effect of defined carbon nanostructures is given by $\mathrm{Wu}$ and Cheng. ${ }^{85}$

Imamura et al. ${ }^{86}$ reported on the enhanced hydrogen absorption properties for supported $\mathrm{Mg}$ nanoparticles that were synthesized by solution impregnation of activated carbon (1040 $\mathrm{m}^{2} \mathrm{~g}^{-1}$ ) with magnesium dissolved in ammonia. Also carbon aerogels $\left(d_{\text {pore }}=13 \mathrm{~nm}\right)$ have been infiltrated with a solution of dibutylmagnesium $\left(\mathrm{MgBu}_{2}\right)$ in heptane. The supported $\mathrm{MgH}_{2}$ nanoparticles were obtained by hydrogenation of $\mathrm{MgBu}_{2}$ and exhibited dehydrogenation kinetics $>5$ times faster compared to the $\mathrm{MgH}_{2}$ reference that was ball-milled with graphite. ${ }^{87}$

Supported magnesium nanoparticles of varying size were prepared using melt infiltration of porous carbons with different pore size. ${ }^{84}$ Even though nanoparticles smaller than $2 \mathrm{~nm}$ can be synthesized with this approach, no thermodynamic effect on the hydrogen sorption properties is reported so far. However, improved kinetics and cyclability are reported, especially when adding small amounts of $\mathrm{Ni}$ as catalyst. ${ }^{6,88}$ The wetting of 
a

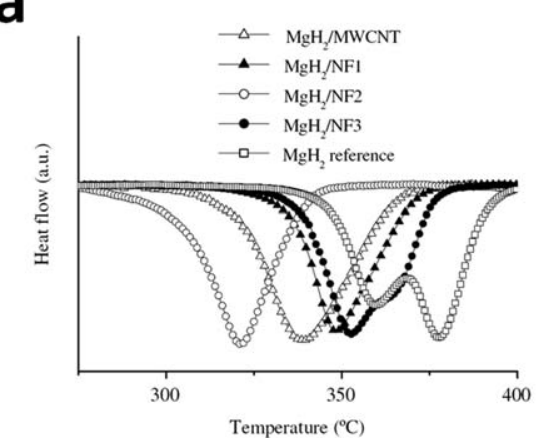

b

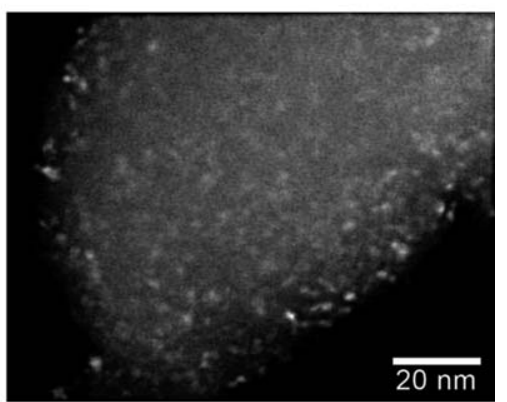

Fig. 5 (a) Hydrogen release from $\mathrm{MgH}_{2}$ after ball milling for $2 \mathrm{~h}$ with ( $5 \mathrm{wt} \%$ ) and without different carbon materials: (MWCNT) multi-walled carbon nanotubes and (NF1-3) carbon nanofibers with increasing surface area. (Data obtained with DSC, $5{ }^{\circ} \mathrm{C} \mathrm{min}{ }^{-1}$, Ar flow.) Reprinted from ref. 35 , with permission from Elsevier. (b) Dark-field TEM image of a nanoporous carbon after melt infiltration with $33 \mathrm{wt} \% \mathrm{Mg}$. The well dispersed $\mathrm{Mg}$ nanoparticles can be seen as bright spots. Reprinted from ref. 84. Copyright 2007 American Chemical Society.

magnesium is enhanced by distributing $\mathrm{Ni}$ or $\mathrm{Cu}$ metal nanoparticles on the carbon matrix before melt infiltration. Composites containing more than $80 \mathrm{wt} \% \mathrm{Mg}$ can be prepared this way, ${ }^{68}$ however, also crystalline $\mathrm{Mg}$ was found by XRD when exceeding weight loadings of approx. $15 \mathrm{wt} \%$. Care has to be taken during preparation as magnesium has a comparably high vapor pressure and can easily oxidize at the infiltration temperature $\left(T_{\mathrm{m}, \mathrm{Mg}}=650^{\circ} \mathrm{C}\right)$.

In summary, the kinetics of the $\mathrm{MgH}_{2}$ system can be significantly enhanced by supporting it on carbon or by adding carbon materials during ball-milling. The cyclability is improved, as carbon reduces particle agglomeration and growth. Even though beneficial thermodynamic effects are predicted from theory, ${ }^{3,71,72}$ no effect on the thermodynamics using carbon as additive or support has been reported in open literature so far. However, it is worth to note that a slight decrease in the thermodynamic stability by $2.84 \mathrm{~kJ} \mathrm{~mol}^{-1}$ was recently found for $\mathrm{Mg}$ nanoparticles of $\sim 7 \mathrm{~nm}$ in size which were embedded in a $\mathrm{LiCl}$ matrix by ball-milling. ${ }^{89}$

\section{Sodium alanate, $\mathrm{NaAlH}_{4}$}

$\mathrm{NaAlH}_{4}$ is the most studied complex hydride, as it is one of the few compounds that combines viable thermodynamical properties $^{90}$ and a relatively high hydrogen storage capacity. Sodium alanate decomposes in three steps upon heating, releasing 7.4 wt $\% \mathrm{H}_{2}$ per $\mathrm{NaAlH}_{4}$ :

$$
\begin{gathered}
3 \mathrm{NaAlH}_{4} \rightarrow \mathrm{Na}_{3} \mathrm{AlH}_{6}+2 \mathrm{Al}+3 \mathrm{H}_{2} \\
\left(\Delta H=36.7 \mathrm{~kJ} \mathrm{~mol}^{-1} \mathrm{H}_{2}, 3.73 \mathrm{wt} \% \mathrm{H}, 33{ }^{\circ} \mathrm{C}\right) \\
\mathrm{Na}_{3} \mathrm{AlH}_{6} \rightarrow \mathrm{Al}+3 \mathrm{NaH}+3 / 2 \mathrm{H}_{2} \\
\left(\Delta H=46.4 \mathrm{~kJ} \mathrm{~mol}^{-1} \mathrm{H}_{2}, 1.87 \mathrm{wt} \% \mathrm{H}, 110{ }^{\circ} \mathrm{C}\right) \\
\mathrm{NaH} \rightarrow \mathrm{Na}+1 / 2 \mathrm{H}_{2} \\
\left(\Delta H=112.8 \mathrm{~kJ} \mathrm{~mol}^{-1} \mathrm{H}_{2}, 1.87 \mathrm{wt} \% \mathrm{H}, 425^{\circ} \mathrm{C}\right)
\end{gathered}
$$

Even though reactions (I) and (II) should occur at $33^{\circ} \mathrm{C}$ and 110 ${ }^{\circ} \mathrm{C}$ under atmospheric hydrogen pressure the course of the reactions is strongly kinetically hindered and substantial decomposition of bulk $\mathrm{NaAlH}_{4}$ only starts after reaching the melting point $\left(T_{\mathrm{m}}=180^{\circ} \mathrm{C}\right)$. $\mathrm{NaH}$ reaches an equilibrium pressure of $1 \mathrm{bar}$ $\mathrm{H}_{2}$ only at $425^{\circ} \mathrm{C}$. Generally speaking, the challenges for reactions (I) and (II) are to use/find suitable catalysts, such as $\mathrm{Ti}^{\mathbf{9 1 , 9 2}}$ and to prevent phase segregation into larger domains of $\mathrm{Al}$ and $\mathrm{NaH}$ upon dehydrogenation that hampers the reversibility of the reactions. $\mathrm{NaH}$ decomposes at temperatures too high for practical use, unless the thermodynamics of reaction (III) could be significantly altered. As will be shown, all these challenges can be tackled by using carbon as support.

It was first noted in 2000 that $\mathrm{NaAlH}_{4}$ ball-milled with carbon exhibits significantly improved hydrogen sorption properties compared to conventionally milled $\mathrm{NaAlH}_{4}{ }^{27} \mathrm{Fig}$. 6 a shows the decomposition of $\mathrm{NaAlH}_{4}$ at $160{ }^{\circ} \mathrm{C}$ with and without $10 \mathrm{wt} \%$ carbon (the nature of the carbon was not further specified). The reaction rates of reactions (I) and (II) increased and improved rehydrogenation behavior was found. ${ }^{78,93,94}$ Since then, several carbon materials have been tested. For graphite, it is suggested that its beneficial effect on the milling process might be due to a dual function, i.e. dry lubricant and micro-grinding agent as a result of carbide formation. ${ }^{95}$

It was also reported that significant improvements can be also obtained by simple mixing of $\mathrm{NaAlH}_{4}$ with carbon materials. ${ }^{43,96}$ Even for $\mu \mathrm{m}$ sized $\mathrm{NaAlH}_{4}$ particles, a strong shift in the dehydrogenation maxima (reactions (I)-(III)) to lower temperatures was observed. In a study using $18 \mathrm{wt} \% \mathrm{CNT}, \mathrm{C}_{60}$ and graphite dispersed in $\mathrm{NaAlH}_{4}, \mathrm{C}_{60}$ was identified as most active carbon modification, as it interfaced most of its surface to the $\mathrm{NaAlH}_{4} \cdot{ }^{97}$ In the same work, the catalytic effect of carbon on the de- and rehydrogenation of $\mathrm{NaAlH}_{4}$ was also explained with its electronegative nature. The bonds in $\mathrm{NaAlH}_{4}$ are ionic between $\mathrm{Na}^{+}$ and $\mathrm{AlH}_{4}{ }^{-}$and covalent between $\mathrm{Al}$ and $\mathrm{H}$. It is suggested that the presence of the electronegative carbon affects the ability of $\mathrm{Na}$ to donate the electron to $\mathrm{AlH}_{4}$, therefore weakening the $\mathrm{Al}-\mathrm{H}$ bonds and thus allowing easier hydrogen release and uptake, although it remains a question whether electronic effects could extend beyond 1-2 $\mathrm{nm}$ in ionic materials.

Solution impregnation was used to synthesize $\mathrm{NaAlH}_{4}$ nanoparticles on CNF $\left(130 \mathrm{~m}^{2} \mathrm{~g}^{-1}\right)$ using THF as solvent. ${ }^{7,98}$ Nanoparticles of different size were prepared by varying the synthesis 
a

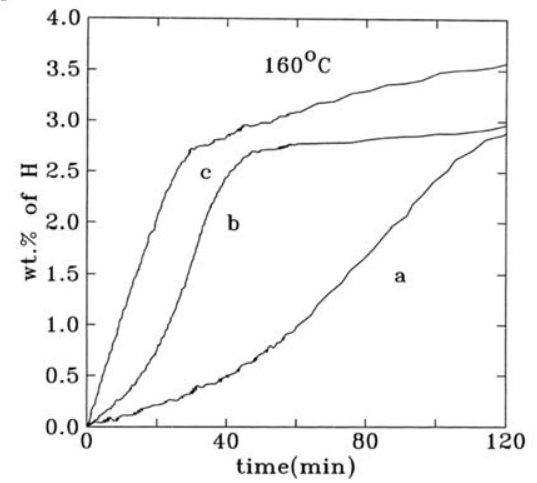

b

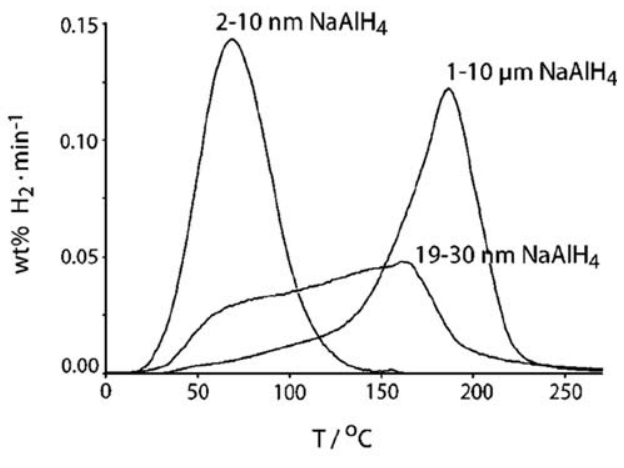

Fig. 6 Kinetic effects on the hydrogen release from $\mathrm{NaAlH}_{4}$ : (a) Decomposition of ball-milled $\mathrm{NaAlH}_{4}$ at $160^{\circ} \mathrm{C}$. $a 1^{\text {st }}$ Decomposition without carbon. $b$ and $c 1^{\text {st }}$ and $2^{\text {nd }}$ decomposition with $10 \mathrm{wt} \%$ carbon. Reprinted from ref. 27 with permission from Elsevier. (b) Hydrogen release (TPD, $5^{\circ} \mathrm{C}$ min ${ }^{-1}, \mathrm{Ar}$ flow) from $\mathrm{NaAlH}_{4}$ particles of different sizes deposited on carbon nanofibers (CNF). Reprinted with permission from ref. 7. Copyright 2008 American Chemical Society.

conditions and a quantitative relation between particle size and the activation energy for $\mathrm{H}_{2}$ release was found. For the smallest particles $\left(d=2-10 \mathrm{~nm}, 2 \mathrm{wt} \% \mathrm{NaAlH}_{4}\right)$, an activation energy of $58 \mathrm{~kJ} \mathrm{~mol}^{-1}$ was found, i.e. much lower than the activation energy for $\mu \mathrm{m}$-sized particles $\left(116 \mathrm{~kJ} \mathrm{~mol}^{-1}\right)$ or Ti catalyzed $\mathrm{NaAlH}_{4}$. The maximum hydrogen release rate (under Ar) was found to be around $60{ }^{\circ} \mathrm{C}$ compared to $180{ }^{\circ} \mathrm{C}$ for bulk $\mathrm{NaAlH}_{4}$ (Fig. 6b).

$\mathrm{NaAlH}_{4}$ melt infiltration has to be conducted in an autoclave, as the liquid $\mathrm{NaAlH}_{4}$ phase $\left(T_{\mathrm{m}, \mathrm{NaAlH}_{4}}=180^{\circ} \mathrm{C}\right)$ is only stable at hydrogen pressures above 130 bar. ${ }^{91}$ Carbon aerogels, ${ }^{100,101}$ high surface area carbon ${ }^{102}\left(500 \mathrm{~m}^{2} \mathrm{~g}^{-1}\right)$ and activated carbon fibers ${ }^{99}$ $\left(1815 \mathrm{~m}^{2} \mathrm{~g}^{-1}\right)$ were tested for this purpose. In a detailed study on the melt infiltration process, it was found that the pore filling is a relatively fast process and that the confinement in the carbon nanopores $(2-3 \mathrm{~nm})$ yields a $\mathrm{NaAlH}_{4}$ phase without long range crystallinity. ${ }^{103}$ Similar to earlier works, only Al but no $\mathrm{NaH}$ or $\mathrm{Na}$ diffraction lines was found by XRD after dehydrogenation. ${ }^{7,43}$ This indicates a higher dispersion of $\mathrm{Na}(\mathrm{H})$ compared to $\mathrm{Al}$, which might be due to a stronger interaction of $\mathrm{Na}(\mathrm{H})$ with the carbon support. Enhanced kinetics and improved reversibility compared to bulk $\mathrm{NaAlH}_{4}$ were reported by all groups. However, of greater importance is the effect on the thermodynamic properties: two groups reported a change in the thermodynamic properties of the $\mathrm{NaAlH}_{4}$ system due to the nanosize and confinement in the porous carbon matrix.99,102,104 Both groups used carbons of high purity, i.e. negligible metal content and with pores in the micro- and mesopore range. Fig. 7 shows the pressure-composition-isotherms (PCIs) of $\mathrm{CeCl}_{3}$ catalyzed bulk $\mathrm{NaAlH}_{4}$ in comparison with nanoconfined $\mathrm{NaAlH}_{4}$. Interestingly, the typical two step behavior (reactions (I) and (II)) is found to be absent for the nanoconfined $\mathrm{NaAlH}_{4}$. Instead, the PCI of the nanoconfined $\mathrm{NaAlH}_{4}$ shows more the behavior of a solid solution. Also it was found that during rehydrogenation in the stability region of the $\mathrm{Na}_{3} \mathrm{AlH}_{6}, \mathrm{NaAlH}_{4}$ forms instead directly from $\mathrm{NaH}, \mathrm{Al}$ and $3 / 2 \mathrm{H}_{2}$. The absence of $\mathrm{Na}_{3} \mathrm{AlH}_{6}$ in the carbon nanoconfinement was confirmed by NMR measurements. ${ }^{102}$ The results point on an interesting fact: whereas $\mathrm{MgH}_{2}$ is predicted to thermodynamically destabilize upon nanosizing and confinement, $\mathrm{NaAlH}_{4}$ seems to be stabilized by confinement in a nanoporous carbon support. However, further experimental and theoretical work is important to determine how exactly $\mathrm{Na}_{3} \mathrm{AlH}_{6}$ and $\mathrm{NaAlH}_{4}$ are thermodynamically altered by the confinement and close contact to the carbon matrix. ${ }^{105}$

The kinetics and thermodynamics of reaction (III) also change for $\mathrm{NaH}$ being in contact with a porous carbon material. Even for bare mixtures of $\mathrm{NaH}$ and carbon, the dehydrogenation

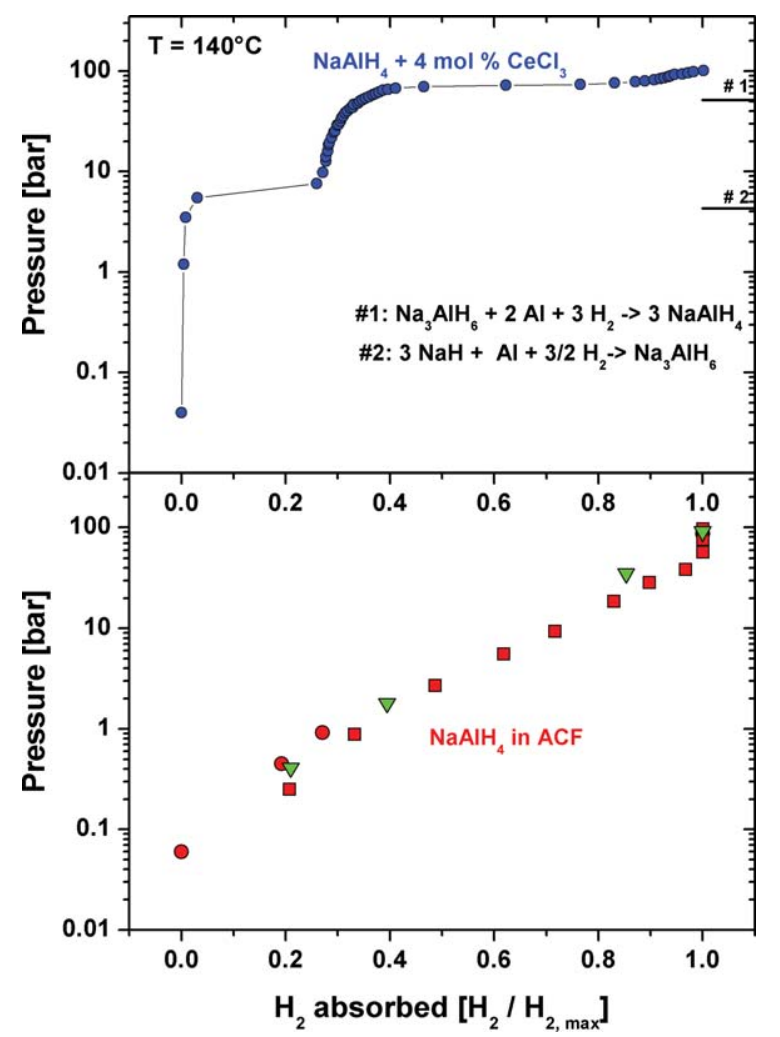

Fig. 7 Thermodynamic effects on carbon supported $\mathrm{NaAlH}_{4}$ : isotherm of $\mathrm{CeCl}_{3}$ catalyzed $\mathrm{NaAlH}_{4}$ showing the equilibria conditions of reactions (I) and (II), and isotherm of $\mathrm{NaAlH}_{4}$ after melt infiltration of activated carbon fibers (ACF, $48 \mathrm{wt} \% \mathrm{NaAlH}_{4}$ ). The isotherms are normalized on the maximum hydrogen capacity obtained for the samples. Courtesy: W. Lohstroh, adapted from ref. 99. 
temperatures under Ar can decrease by more than $100^{\circ} \mathrm{C}$. Upon heating of $\mathrm{NaH} /$ carbon mixtures and dehydrogenation, liquid $\mathrm{Na}\left(T_{\mathrm{m}, \mathrm{Na}}=97.7{ }^{\circ} \mathrm{C}\right)$ readily infiltrates the porous carbon structure. Fig. 8a shows a series of XRD patterns starting from the $\mathrm{NaH} /$ carbon mixture. After dehydrogenation (melt infiltration) one can see a broad $\mathrm{Na}$ diffraction line indicative for nanosized crystallites and a clear shift of the (002) diffraction line around $30^{\circ}$ towards lower scattering angles due to intercalation of the carbon matrix.

Deintercalation occurs upon gradual rehydrogenation. As a result of intercalation and interaction with the carbon matrix, the equilibrium hydrogen pressure of carbon supported $\mathrm{NaH}$ is partially shifted to higher values with hydrogen release under
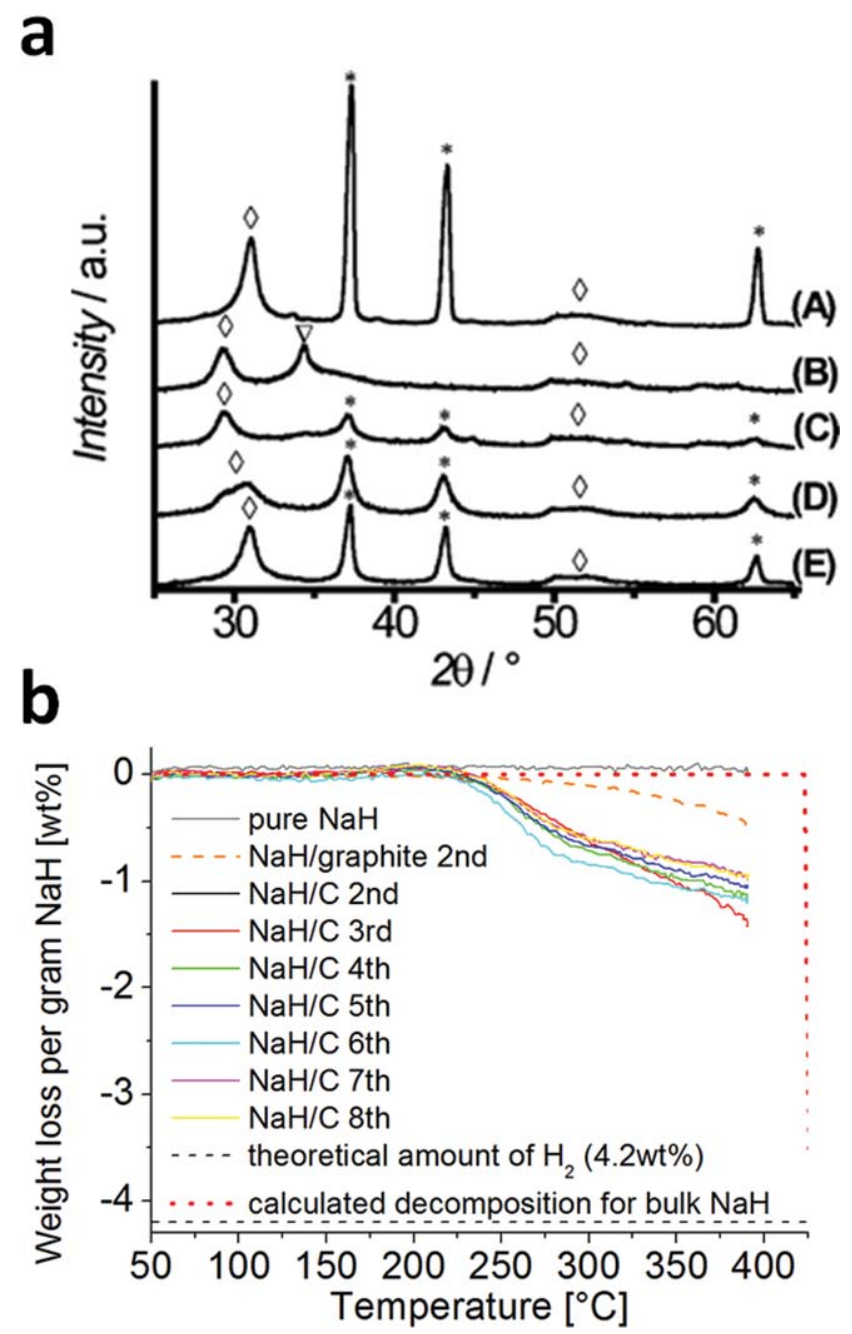

Fig. 8 Thermodynamic effects on carbon supported NaH: (a) XRD patterns of samples containing $33 \mathrm{wt} \% \mathrm{NaH}$ on carbon. (A) Physical mixture of $\mathrm{NaH}$ and carbon for comparison. (B) After Na melt infiltration: intercalation leads to a shift of the (002) carbon diffraction line around $30^{\circ}$ towards lower scattering angles. (C-E) Deintercalation upon gradual rehydrogenation of $\mathrm{Na} . \diamond=$ carbon, ${ }^{*}=\mathrm{NaH}$, and $\nabla=\mathrm{Na}$. (b) Hydrogen release from the nanocomposite $(\mathrm{NaH} / \mathrm{C})$ under atmospheric hydrogen pressure. Numbers indicate the cycle. The decomposition temperature of crystalline $\mathrm{NaH}$ is indicated for comparison..$^{43}$ Reproduced with permission of The Royal Society of Chemistry.
1 bar $\mathrm{H}_{2}$ starting from around $225^{\circ} \mathrm{C}$, which is $200{ }^{\circ} \mathrm{C}$ below than what is expected for bulk NaH (Fig. 8b). ${ }^{43}$

In summary, the $\mathrm{NaAlH}_{4}$-carbon system is an excellent example of how strongly a carbon material can influence both kinetics of hydrogen release and uptake, as well as the thermodynamics, of a hydrogen storage material. Hydrogen release from $\mathrm{NaAlH}_{4}$ and $\mathrm{NaH}$ is even facilitated by bare mixing with carbon materials. A change in thermodynamics occurs for $\mathrm{NaAlH}_{4}$ and $\mathrm{NaH}$ confined in the pores of micro/mesoporous carbons.

\section{Conclusion}

In this review we have discussed the impact of carbon materials on the hydrogen storage properties of metal hydrides. Nanosizing and nanoconfining are promising routes to meet the kinetic and thermodynamic requirements necessary for practical application and both routes are accessible by using carbon materials as support or additive. Additionally carbon materials are light and low in cost, which makes them an ideal match for the preparation of metal hydrides based nanocomposites.

In general, carbon materials act as effective catalysts and improve the reversibility of the de- and rehydrogenation reaction, as growth of the metal hydride nanoparticles and crystallites is hindered upon cycling. As carbon materials are not classical catalysts, their strong effect on the kinetics is still a matter of debate probably owing to their complex microstructure. Especially terminating groups that include heteroatoms such as $\mathrm{H}, \mathrm{N}$ or $\mathrm{O}$ or intrinsic defects might play an important role. Further insight in the catalytic effect of carbon on metal hydrides might be therefore gained by including heteroatoms or defects in theoretical model systems. Many carbon materials often also contain metallic impurities that can further improve the kinetics. This synergetic effect was found for ball-milled $\mathrm{MgH}_{2} /$ carbon nanocomposites, for example. Surprisingly, enhanced hydrogen release is also found for bare mixtures of micrometre sized carbon particles with $\mathrm{NaAlH}_{4}$ or $\mathrm{NaH}$, indicating that not only nanoeffects are responsible for the kinetic improvements in this system but also the carbon phase itself has an important role.

As an important point, it was shown that also the thermodynamic properties can be altered by supporting metal hydrides on a carbon support. For the $\mathrm{NaAlH}_{4}$ system this change is two-fold. Whereas $\mathrm{NaAlH}_{4}$ seems to be stabilized by the nanoconfinement, $\mathrm{NaH}$ is destabilized (at least partly due to intercalation effects). The impact on the thermodynamics is found for confinement in pores below a few nanometres size. Thus carbon materials with large pore volumes in the micro- and mesopore range are desirable to allow high weight loadings of the hydride. Further information on the size effect might be obtained by using ordered mesoporous and carbide derived carbons as support. However, it will remain a challenge to separate the effects of particle size, confinement, surface chemistry, etc.

In summary it is clearly demonstrated that the use of carbon materials offers many opportunities in tailoring the properties of metal hydrides. As their porosity and surface chemistry can be adjusted in a broad range, their use as support thus shows great potential for further improvements in hydrogen storage applications. 


\section{References}

1 L. Schlapbach and A. Zuttel, Nature, 2001, 414, 353-358.

2 Targets for Onboard Hydrogen Storage Systems for Light-Duty Vehicles, http://www1.eere.energy.gov/hydrogenandfuelcells/ storage/pdfs/targets_onboard_hydro_storage_explanation.pdf.

3 J. J. Liang and W. C. P. Kung, J. Phys. Chem. B, 2005, 109, 1783717841.

4 V. Berube, G. Chen and M. S. Dresselhaus, Int. J. Hydrogen Energy, 2008, 33, 4122-4131.

5 V. Berube, G. Radtke, M. Dresselhaus and G. Chen, Int. J. Energy Res., 2007, 31, 637-663.

6 P. E. de Jongh and P. Adelhelm, in Handbook of Hydrogen Storage, ed. M. Hirscher, Wiley-VCH, Weinheim, 2010.

7 C. P. Balde, B. P. C. Hereijgers, J. H. Bitter and K. P. de Jong, J. Am. Chem. Soc., 2008, 130, 6761-6765.

8 N. Iwashita, C. R. Park, H. Fujimoto, M. Shiraishi and M. Inagaki, Carbon, 2004, 42, 701-714.

9 A. C. Ferrari and J. Robertson, Phys. Rev. B: Condens. Matter Mater. Phys., 2000, 61, 14095-14107.

10 J.-B. Donnet, Carbon Black-Science and Technology, Dekker, New York, 1993.

11 A. D. McNaught and A. Wilkinson, in Compendium of Chemical Terminology, Blackwell Scientific Publications, Oxford, 1997.

12 N. Husing and U. Schubert, Angew. Chem., Int. Ed., 1998, 37, 2345.

13 N. Job, A. Théry, R. Pirard, J. Marien, L. Kocon, J.-N. Rouzaud, F. Béguin and J.-P. Pirard, Carbon, 2005, 43, 2481-2494.

14 A. C. Pierre and G. M. Pajonk, Chem. Rev., 2002, 102, 4243-4265.

15 G. Reichenauer, A. Emmerling, J. Fricke and R. W. Pekala, J. NonCryst. Solids, 1998, 225, 210-214.

16 R. Ryoo, S. H. Joo and S. Jun, J. Phys. Chem. B, 1999, 103, 77437746.

17 S. Jun, S. H. Joo, R. Ryoo, M. Kruk, M. Jaroniec, Z. Liu, T. Ohsuna and O. Terasaki, J. Am. Chem. Soc., 2000, 122, 10712-10713.

18 R. Ryoo, S. H. Joo, M. Kruk and M. Jaroniec, Adv. Mater., 2001, 13, 677-681.

19 J. Lee, J. Kim and T. Hyeon, Adv. Mater., 2006, 18, 2073-2094.

20 Y. Gogotsi, A. Nikitin, H. H. Ye, W. Zhou, J. E. Fischer, Y. Bo, H. C. Foley and M. W. Barsoum, Nat. Mater., 2003, 2, 591-594.

21 Y. G. Gogotsi and M. Yoshimura, Nature, 1994, 367, 628-630.

22 T. J. Barton, L. M. Bull, W. G. Klemperer, D. A. Loy, B. McEnaney, M. Misono, P. A. Monson, G. Pez, G. W. Scherer, J. C. Vartuli and O. M. Yaghi, Chem. Mater., 1999, 11, 2633-2656.

23 K. P. de Jong and J. W. Geus, Catal. Rev. Sci. Eng., 2000, 42, 481510.

24 D. M. Guldi, A. Rahman, V. Sgobba and C. Ehli, Chem.Soc. Rev., 2006, 35, 471-487.

25 R. Taylor and D. R. M. Walton, Nature, 1993, 363, 685-693.

26 A. Zaluska, L. Zaluski and J. O. Strom-Olsen, J. Alloys Compd., 1999, 288, 217-225.

27 A. Zaluska, L. Zaluski and J. O. Strom-Olsen, J. Alloys Compd., 2000, 298, 125-134.

28 J. Huot, G. Liang and R. Schulz, Appl. Phys. A: Mater. Sci. Process., 2001, 72, 187-195.

29 M. Fichtner, Adv. Eng. Mater., 2005, 7, 443-455.

30 M. U. Niemann, S. S. Srinivasan, A. R. Phani, A. Kumar, D. Y. Goswami and E. K. Stefanakos, J. Nanomater., 2008, DOI: $10.1155 / 2008 / 950967$.

31 K. F. Aguey-Zinsou and J. R. Ares-Fernández, Energy Environ. Sci., 2010, 3, 526-543.

32 Z. Dehouche, T. Klassen, W. Oelerich, J. Goyette, T. K. Bose and R. Schulz, J. Alloys Compd., 2002, 347, 319-323.

33 O. Friedrichs, F. Aguey-Zinsou, J. R. A. Fernandez, J. C. SanchezLopez, A. Justo, T. Klassen, R. Bormann and A. Fernandez, Acta Mater., 2006, 54, 105-110.

34 N. Pierard, A. Fonseca, J. F. Colomer, C. Bossuot, J. M. Benoit, G. Van Tendeloo, J. P. Pirard and J. B. Nagy, Carbon, 2004, 42, $1691-1697$.

35 M. A. Lillo-Rodenas, Z. X. Guo, K. F. Aguey-Zinsou, D. CazorlaAmoros and A. Linares-Solano, Carbon, 2008, 46, 126-137.

36 Z. Z. Fang, X. D. Kang, P. Wang and H. M. Cheng, J. Phys. Chem. $C, 2008,112,17023-17029$.

37 V. P. Balema, V. K. Pecharsky and K. W. Dennis, J. Alloys Compd., 2000, 313, 69-74.
38 T. Etter, A. Papakyriacou, P. Schulz and P. J. Uggowitzer, Carbon, 2003, 41, 1017-1024.

39 M. S. Dresselhaus and G. Dresselhaus, Adv. Phys., 2002, 51, $1-186$.

40 M. Noel and V. Suryanarayanan, J. Power Sources, 2002, 111, $193-$ 209.

41 H. Selig and L. B. Ebert, in Advances in Inorganic Chemistry and Radiochemistry, ed. H. J. Emeleus and A. G. Sharpe, Academic press, Inc., 1980, pp. 281-327.

42 V. V. Avdeev, A. P. Savchenkova, L. A. Monyakina, I. V. Nikolskaya and A. V. Khvostov, J. Phys. Chem. Solids, 1996, 57, 947-949.

43 P. Adelhelm, K. P. de Jong and P. E. de Jongh, Chem. Commun., 2009, 6261-6263.

44 T. Enoki, S. Miyajima, M. Sano and H. Inokuchi, J. Mater. Res., 1990, 5, 435-466.

45 H. Miyaoka, T. Ichikawa and Y. Kojima, Nanotechnology, 2009, 20, 204021.

46 H. Miyaoka, K. Itoh, T. Fukunaga, T. Ichikawa, Y. Kojima and H. Fuji, J. Appl. Phys., 2008, 104, 053511.

47 X. B. Yu, Z. Wu, Q. R. Chen, Z. L. Li, B. C. Weng and T. S. Huang, Appl. Phys. Lett., 2007, 90, 034106.

48 H. P. Boehm, W. Heck, R. Sappok and E. Diehl, Angew. Chem., Int. Ed. Engl., 1964, 3, 669-677.

49 R. J. J. Jansen and H. van Bekkum, Carbon, 1994, 32, 1507-1516.

50 R. J. J. Jansen and H. van Bekkum, Carbon, 1995, 33, 1021-1027.

51 F. Rodriguez-Reinoso, Carbon, 1998, 36, 159-175.

52 J. L. Figueiredo, M. F. R. Pereira, M. M. A. Freitas and J. J. M. Orfao, Carbon, 1999, 37, 1379-1389.

53 H. Q. Jiang, F. Chen, M. G. Lagally and F. S. Denes, Langmuir, 2010, 26, 1991-1995.

54 Q. H. Yang, W. H. Xu, A. Tomita and T. Kyotani, Chem. Mater., 2005, 17, 2940-2945.

55 F. Jaouen, M. Lefevre, J. P. Dodelet and M. Cai, J. Phys. Chem. B, $2006,110,5553-5558$.

56 M. Terrones, A. G. Souza and A. M. Rao, in Carbon Nanotubes, Springer-Verlag, Berlin, 2008, pp. 531-566.

57 D. S. Su, J. Zhang, B. Frank, A. Thomas, X. C. Wang, J. Paraknowitsch and R. Schlogl, ChemSusChem, 2010, 3, 169-180.

58 J. M. Carlsson and M. Scheffler, Phys. Rev. Lett., 2006, 96, 046806.

59 J. I. Paredes, A. Martinez-Alonso and J. M. D. Tascon, Carbon, 2000, 38, 1183-1197.

60 R. Arrigo, PhD thesis, Nitrogen Functionalization of CNFs and Application in Heterogeneous Catalysis, Technical University Berlin, Berlin, 2009.

61 T. W. Ebbesen, Carbon Nanotubes: Preparation and Properties, CRC Press, Inc., Boca Raton, 1996.

62 H. P. Boehm, Carbon, 2002, 40, 145-149.

63 H. Aso, K. Matsuoka and A. Tomita, Abstr. Pap. Am. Chem. Soc., 2003, 225, 009-ENVR.

64 J. P. Tessonnier, D. Rosenthal, T. W. Hansen, C. Hess, M. E. Schuster, R. Blume, F. Girgsdies, N. Pfander, O. Timpe, D. S. Su and R. Schlogl, Carbon, 2009, 47, 1779-1798.

65 F. Kohlrausch, Praktische Physik, B.G. Teubner, Stuttgart, 1986, vol. 3.

66 K. J. Kim, B. Montoya, A. Razani and K. H. Lee, Int. J. Hydrogen Energy, 2001, 26, 609-613.

67 A. R. Sanchez, H. P. Klein and M. Groll, Int. J. Hydrogen Energy, 2003, 28, 515-527.

68 R. Bogerd, P. Adelhelm, J. H. Meeldijk, K. P. de Jong and P. E. de Jongh, Nanotechnology, 2009, 20, 204019.

69 M. A. Lio-Rodenas, K. F. Aguey-Zinsou, D. Cazorla-Amoros, A. Linares-Solano and Z. X. Guo, J. Phys. Chem. C, 2008, 112, 5984-5992.

70 C. Z. Wu, P. Wang, X. D. Yao, C. Liu, D. M. Chen, G. Q. Lu and H. M. Cheng, J. Phys. Chem. B, 2005, 109, 22217-22221.

71 S. Cheung, W. Q. Deng, A. C. T. van Duin and W. A. Goddard, J. Phys. Chem. A, 2005, 109, 851-859.

72 R. W. P. Wagemans, J. H. van Lenthe, P. E. de Jongh, A. J. van Dillen and K. P. de Jong, J. Am. Chem. Soc., 2005, 127, 1667516680 .

73 S. Nohara, H. Inoue, Y. Fukumoto and C. Iwakura, J. Alloys Compd., 1997, 252, L16-L18.

74 S. Bouaricha, J. P. Dodelet and D. Guay, J. Mater. Res., 2001, 16, 2893-2905. 
75 S. Bouaricha, J. P. Dodelet, D. Guay, J. Huot and R. Schulz, J. Alloys Compd., 2001, 325, 245-251.

76 J. L. Bobet, B. Chevalier, M. Y. Song and B. Darriet, J. Alloys Compd., 2003, 356, 570-574.

77 B. S. Amirkhiz, M. Danaie, M. Barnes, B. Simard and D. Mitlin, J. Phys. Chem. C, 2010, 114, 3265-3275.

78 B. S. Amirkhiz, M. Danaie and D. Mitlin, Nanotechnology, 2009, 20, 204016.

79 X. D. Yao, C. Z. Wu, A. J. Du, G. Q. Lu, H. M. Cheng, S. C. Smith, J. Zou and Y. H. He, J. Phys. Chem. B, 2006, 110, 11697-11703.

80 X. D. Yao, C. Z. Wu, A. J. Du, J. Zou, Z. H. Zhu, P. Wang, H. M. Cheng, S. Smith and G. Q. Lu, J. Am. Chem. Soc., 2007, 129, 15650-15654.

81 C. Z. Wu, P. Wang, X. Yao, C. Liu, D. M. Chen, G. Q. Lu and H. M. Cheng, J. Alloys Compd., 2006, 414, 259-264.

82 C. Z. Wu, P. Wang, X. Yao, C. Liu, D. M. Chen, G. Q. Lu and H. M. Cheng, J. Alloys Compd., 2006, 420, 278-282.

83 A. J. Du, S. C. Smith, X. D. Yao and G. Q. Lu, J. Phys. Chem. B, 2006, 110, 1814-1819.

84 P. E. de Jongh, R. W. P. Wagemans, T. M. Eggenhuisen, B. S. Dauvillier, P. B. Radstake, J. D. Meeldijk, J. W. Geus and K. P. de Jong, Chem. Mater., 2007, 19, 6052-6057.

85 C. Z. Wu and H. M. Cheng, J. Mater. Chem., 2010, 20, 5390-5400.

86 H. Imamura, Y. Usui and M. Takashima, J. Less Common Met., 1991, 175, 171-176.

87 S. Zhang, A. F. Gross, S. L. Van Atta, M. Lopez, P. Liu, C. C. Ahn, J. J. Vajo and C. M. Jensen, Nanotechnology, 2009, 20, 204027.

88 A. F. Gross, C. C. Ahn, S. L. Van Atta, P. Liu and J. J. Vajo, Nanotechnology, 2009, 20, 204005.

89 M. Paskevicius, D. A. Sheppard and C. E. Buckley, J. Am. Chem. Soc., 2010, 132, 5077-5083.

90 B. M. Lee, J. W. Jang, J. H. Shim, Y. W. Cho and B. J. Lee, J. Alloys Compd., 2006, 424, 370-375.
91 B. Bogdanovic, R. A. Brand, A. Marjanovic, M. Schwickardi and J. Tolle, J. Alloys Compd., 2000, 302, 36-58.

92 B. Bogdanovic and M. Schwickardi, J. Alloys Compd., 1997, 253, 1-9. 93 Z. Dehouche, L. Lafi, N. Grimard, J. Goyette and R. Chahine, Nanotechnology, 2005, 16, 402-409.

94 J. Wang, A. D. Ebner and J. A. Ritter, J. Phys. Chem. B, 2006, 110, $17353-17358$

95 J. Wang, A. D. Ebner, T. Prozorov, R. Zidan and J. A. Ritter, J. Alloys Compd., 2005, 395, 252-262.

96 C. Cento, P. Gislon, M. Bilgili, A. Masci, Q. Zheng and P. P. Prosini, J. Alloys Compd., 2007, 437, 360-366.

97 P. A. Berseth, A. G. Harter, R. Zidan, A. Blomqvist, C. M. Araujo, R. H. Scheicher, R. Ahuja and P. Jena, Nano Lett., 2009, 9, 15011505.

98 C. P. Balde, B. P. C. Hereijgers, J. H. Bitter and K. P. de Jong, Angew. Chem., Int. Ed., 2006, 45, 3501-3503.

99 W. Lohstroh, A. Roth, H. Hahn and M. Fichtner, ChemPhysChem, 2010, 11, 789-792.

100 F. Schueth, B. Bogdanovic and T. Akira, WO/2005/014469, 2004.

101 R. D. Stephens, A. F. Gross, S. L. Van Atta, J. J. Vajo and F. E. Pinkerton, Nanotechnology, 2009, 20, 204018.

102 J. B. Gao, P. Adelhelm, M. H. W. Verkuijlen, C. Rongeat, M. Herrich, P. J. M. van Bentum, O. Gutfleisch, A. P. M. Kentgens, K. P. de Jong and P. E. de Jongh, J. Phys. Chem. C, 2010, 114, 4675-4682.

103 P. Adelhelm, J. B. Gao, M. H. W. Verkuijlen, C. Rongeat, M. Herrich, P. J. M. van Bentum, O. Gutfleisch, A. P. M. Kentgens, K. P. de Jong and P. E. de Jongh, Chem. Mater., 2010, 22, 2233-2238.

104 M. H. W. Verkuijlen, J. B. Gao, P. Adelhelm, P. J. N. van Bentum, P. E. de Jongh and A. P. M. Kentgens, J. Phys. Chem. C, 2010, 114, 4683-4692.

105 T. Mueller and G. Ceder, ACS Nano, 2010, DOI: 10.1021/nn101224j. 